\title{
Adolescent perspectives of the recreational ice hockey food environment and influences on eating behaviour revealed through photovoice
}

\author{
M Susan Caswell* and Rhona M Hanning
}

School of Public Health and Health Systems, University of Waterloo, 200 University Avenue W, Waterloo, Ontario, Canada, N2L 3G1

Submitted 5 June 2017: Final revision received 1 December 2017: Accepted 23 January 2018: First published online 1 March 2018

\begin{abstract}
Objective: Unhealthy dietary behaviours are prevalent among adolescents. This might relate, in part, to obesogenic environments, including recreation food facilities. The REFRESH Study (Recreation Environment and Food Research: Experiences from Hockey) aimed to explore, from the perspectives of adolescent ice hockey players and parents, broad social and physical environmental influences on adolescent food behaviours associated with hockey participation. Design: Players used photovoice to describe their food experiences in relation to ice hockey. The approach included photos, individual interviews and focus groups. Exemplar photographs were exhibited for stakeholders, including five parents who were interviewed. Interview and focus group transcripts were thematically analysed.

Setting: Recreational ice hockey environment, Ontario, Canada, 2015-16.

Subjects: Ice hockey players ( $n$ 24) aged 11-15 years recruited from five leagues. Results: Dominant influences among players included: their perceived importance of nutrients (e.g. protein) or foods (e.g. chocolate milk) for performance and recovery; marketing and branding (e.g. the pro-hockey aura of Tim Horton's ${ }^{\circledR}$, Canada's largest quick-service restaurant); social aspects of tournaments and team meals; and moral values around 'right' and 'wrong' food choices. Both players and parents perceived recreational facility food options as unhealthy and identified that travel and time constraints contributed to less healthy choices.

Conclusions: Results indicate recreation facilities are only one of a range of environments that influence eating behaviours of adolescent ice hockey players. Players' susceptibility to advertising/brand promotion and the value of healthy food choices for performance are findings that can inform policy and interventions to support healthy environments and behaviours.
\end{abstract}

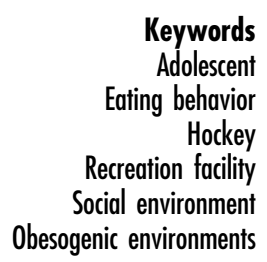

Unhealthy dietary behaviours are prevalent among adolescents and have been identified as a risk factor for obesity and chronic disease such as type 2 diabetes and $\mathrm{CVD}^{(1-5)}$. Significant increases in the prevalence of childhood and adolescent obesity over recent decades have been attributed, in part, to environmental factors, encompassing both physical and social environmental influences ${ }^{(1,5-7)}$. For example, increased consumption of food prepared away from home has been associated with poorer diet quality and has paralleled increases in overweight and obesity prevalence in children and adolescents $^{(8-11)}$. For adolescents involved in organized sports like ice hockey, the national winter sport in Canada and highly popular among youth, recreational facilities are an environment in which they spend a significant amount of time. Yet recreational facility food in Canada is often unhealthy and there is evidence that adolescents who participate in organized sports have higher intakes of fast foods and sugar-sweetened beverages than nonparticipants $^{(12-15)}$.

Research on school food policy has indicated that improved food environments result in improved diet quality, lower energy intake and healthy beverage consumption $^{(16-19)}$. However, the school food policy experience also indicates that addressing the physical environment in isolation is not sufficient; action is needed comprehensively, including education, home and community contexts ${ }^{(16-18,20,21)}$. With evidence that current recreation environments may be 'obesogenic', there is emerging recognition by policy makers and health 
professionals that such environments, as has been the case with schools, have the potential to support healthy eating $^{(14,22-24)}$. Several Canadian provinces are considering policies to increase healthy food offerings in recreation facilities and some provinces have already taken action by instituting voluntary nutrition guidelines ${ }^{(25-27)}$. Ontario, with some municipal-level exceptions, has yet to initiate policy or guidelines.

Will providing healthy food in recreation environments be enough? Obesity prevention is complex and requires consideration of many factors, including contextual factors, that influence food-related decisions and eating behaviours over time ${ }^{(24,28)}$. To date, recreation facility food environment research in Canada has centred predominantly on stakeholders such as facility management and government, but not those regularly exposed to these environments ${ }^{(14,15,23,29-31)}$. There are recognized gaps in evidence linking environmental factors and adolescent dietary intake and a need for adolescent perspectives to be included ${ }^{(7,32-36)}$. Understanding factors influencing adolescents' dietary intake in recreational environments is essential to inform policy and intervention strategies that support healthy eating behaviours. Given their high levels of exposure, adolescent hockey players serve as key informants around expected influences of recreation food environments. Therefore, the objective of the current research was to explore physical and social environmental influences associated with playing ice hockey on adolescent hockey players' food behaviours as perceived by the players themselves and their parents.

\section{Methods}

The present phenomenological study employed a modified photovoice method to elicit deep understanding of the experience of the recreational hockey food environment for adolescent ice hockey players playing minor hockey in Ontario, Canada. Adopting a qualitative approach allows for in-depth understanding of the lived experience while providing the opportunity to identify unanticipated factors ${ }^{(37)}$. Photovoice is a qualitative method that values everyday life experiences and can provide researchers with rich data in diverse settings while giving voice to populations that are influenced by policy, yet have no say in policy development or implementation $^{(38)}$. This methodology is conducive to self-expression and deep exploration of participant experiences ${ }^{(39,40)}$. Photovoice has been demonstrated to be an appropriate methodological approach for gathering adolescent input and involvement in community change ${ }^{(39-41)}$. Community members take photographs to identify, record and reflect on their perceptions and experiences ${ }^{(42,43)}$. Group consensus determines representative photographs to share with stakeholders ${ }^{(42,43)}$. Discussion allows participants to provide meaning and definition to the images and control the selection of photos to best represent their experience, not the researcher's agenda ${ }^{(42-44)}$.

Over a two-week period, participants took photographs reflecting their lived experience. One-on-one semistructured interviews with each participant were used to elucidate and contextualize the photographs. Players then participated in focus group discussions of a representative sample of photographs from which a subset was selected for exhibition to local stakeholders (parents, coaches, etc.). Following the exhibits, hockey players' parents participated in one-on-one semi-structured interviews regarding their perceptions of the food experiences represented.

A purposive sample of twenty-five Ontario ice hockey players aged 11-15 years was recruited through verbal invitation immediately following a hockey practice, poster advertising or word-of-mouth. Recruitment was from male and female minor hockey teams playing at levels above house league, since these players typically practice and play in multiple facilities, participate in hockey activities a minimum of two to three times per week, travel to outof-town (away) games and regularly participate in tournaments. This provided exposure to a variety of food environments in relation to recreational ice hockey. Inclusion criteria for players were as follows:

1. Regular scheduled practice in more than one recreational facility;

2. Aged $\geq 12$ years by the $2015-16$ hockey season end;

3. 'Active' on team during the designated photograph window (i.e. not benched due to injury or illness);

4. Resident of Ontario within $250 \mathrm{~km}$ of the principal investigator (M.S.C.); and

5. Informed parental consent and participant assent obtained.

Participants were instructed to take photographs over a two-week period, chosen to include regular practice, a minimum of two scheduled league games and one tournament to capture the breadth of the recreational hockey food environment. Guidance was provided regarding taking the photographs and ensuring anonymity. The number of photographs was left to the participants. All participants opted to use their own smartphone cameras.

Individual interviews are not a prescribed component of photovoice, but were included to allow participants to share the experience and context of individual photographs without inter-participant influence. Interviews were guided by a protocol comprised of open-ended questions and probes ${ }^{(37,45,46)}$ that had been pilot tested with a convenience sample of the target population ( $n 2$; age $11-15$ years). Following the interview, three to five photographs were selected that best represented their personal experience for focus group and exhibit purposes.

Photographs representing the hockey players' experiences were grouped according to content. Two focus group discussions of photographs with players were 
scheduled after completion of interviews. This integral component of photovoice was guided by M.S.C. using the SHOWeD framework ${ }^{(42,43)}$ :

1. What do you See here?

2. What's really Happening here?

3. How does this relate to Our lives?

4. Why does this situation, concern, or strength exist?

5. What can we Do about it?

A second trained facilitator was present to observe participants and document their physical expressions. Representative photographs were selected for an exhibit for stakeholders at two regional arenas.

Parent perspectives of influences on the food choices of the adolescents in relation to recreational hockey were obtained through interviews stimulated by the photograph exhibit. Inclusion criterion was having a child who met eligibility requirements, but was not necessarily a participant. Invitations to participate were offered: verbally to parents attending the exhibit; directly to parents of study participants; and through coaches of eligible teams. Recruiting continued until no new codes or themes were generated, indicating that data saturation was achieved. Interviews were guided by M.S.C. using open-ended questions, probes and exhibit photographs ${ }^{(37,45,46)}$.

Study player and parent participants received a \$CAN 10 gift card as remuneration.

\section{Analysis}

Interviews and focus group discussions were audio recorded and transcribed verbatim by M.S.C. Participant observations were incorporated into transcripts to contextualize participant behaviours and responses. Transcripts were analysed, supported by NVivo qualitative data analysis software version 11 (QSR International Pty Ltd, Doncaster, Australia, 2015), and coding was conducted using an inductive approach guided by Colaizzi's process for phenomenological research ${ }^{(47)}$. Audio tapes and transcripts were reviewed, significant statements pertainting to experiences of the recreational food environment were extracted, underlying meanings formulated from the significant statements and coded, and then codes aggregated and collapsed into emergent themes. Findings were integrated into a description of the experience of the recreational food environment and the description reduced to the essential form of the experience. A codebook was maintained to ensure standardized and consistent analysis ${ }^{(48)}$. Data saturation was achieved before all players' transcripts had been analysed. As a measure of reliability, a second reader with qualitative research expertise reviewed both focus group transcripts and a subset ( 25\%) of interview transcripts $^{(45)}$. Any variations in coding were discussed to achieve consensus ${ }^{(48)}$. To validate interpretation, participants (n 2) who had attended separate focus group sessions reviewed results and offered feedback to ensure authenic representation of their experience.

\section{Study rigour}

To ensure reliability, credibility and validity, data were triangulated from multiple sources: photographs, one-onone interviews with both players and parents, and player focus groups ${ }^{(45,49)}$. The second reader provided an external check of the data interpretation and analysis $^{(45)}$.

\section{Ethical considerations}

This study received ethics clearance from the University of Waterloo Office of Research Ethics (ORE file \#20568).

Adolescent participants provided informed written assent prior to participation. As participants were minors, informed written consent from a parent or guardian was also obtained. Following the interview, a written release for the use of photographs for focus group and exhibit purposes was received from participants and a parent or guardian.

To ensure participant anonymity, participant quotes are identified by participant number from one-on-one interviews and by focus group and participant number for group discussions.

\section{Results}

\section{Hockey players' perceptions of food influences}

\section{Sample}

Youth participants ranged in age from 11 to 15 years (median 13 years). Twenty-five players were recruited; twenty-three male and two female. Participants represented five minor ice hockey leagues and twelve teams in Ontario. One participant withdrew because no photographs were taken. Photographs (450 total; range 4-53 per player, median $=15$, mean $=19$ ) were submitted by the remaining players. Sixteen players participated in focus groups; ten the first and six the second. Non-participation was due to scheduling conflicts and distance.

\section{Findings}

Results indicate a complex interaction of factors influencing the food choices and behaviours of these adolescent hockey players. Dominant themes around food perceptions included: recreational facilities; performance and recovery; branding and media; morality and values; and tournament influences.

\section{Theme: recreational facilities}

Players considered the food offerings within the recreation facilities to be generally unhealthy and not good for recovery, so when they were finished playing or practising most described wanting to leave immediately or, at most, purchase a beverage. Some stated that while they liked the taste of the foods offered, they 'knew' these choices were not good for them. The players reported that occasionally 
recreation facility foods were eaten as a 'treat' or offered as a reward for playing well but were not a regular part of their hockey food routine.

One interesting perception reported by players was that the food offerings at recreation facilities were there for spectators:

'... if you like look at the stands at like a younger hockey game where all the kids are, they're prob'ly at least a quarter of them will have like popcorn or fries or something like that.' (FG2P4)

The players also indicated that healthier choices should be available, but some players suggested that without unhealthy offerings, facilities would get little business. The players felt tradition was an important aspect of food choices in recreation centres. On the occasions they did eat within recreation facilities, some described expecting to be able to purchase something like fries:

'... but I always would rather have something that would taste better than is healthy at an arena, just 'cuz that's what's there and that's what you kind of think of when you think of arena food.' (P6)

\section{Theme: perceptions of foods and performance}

All players reported the important influence of nutrition on performance. This was represented by attention to intake, attitudes towards, and behaviours around, specific food groups and individual foods or beverages. Dominant sub-themes included protein and fast food.

Protein. All players perceived that protein played an important role in their physical performance. It was considered important for muscle development and 'lots of energy', making protein a cornerstone of their diet related to hockey. Protein was typically depicted in the form of protein-supplemented foods and/or beverages. These included chocolate milk beverages with added protein, protein bars and protein-powder-based smoothies.

A difference in the perceived role of protein was apparent between players who reported being offered specific nutrition guidance around protein intake ( $n$ 6) and those who had not received such guidance. The six who had a nutrition specialist to speak to them early in the season indicated that protein was for replenishment after the game. They recounted the guideline to ingest $20 \mathrm{~g}$ of protein within $20 \mathrm{~min}$ of play or practice to maximize muscle recovery. They felt adhering to the guideline improved their performance. The subgroup provided numerous photographs of protein shakes, fortified beverages and bars which they described consuming in the locker room as part of their immediate off-ice routine.

Those without any nutrition guidance considered protein, typically in the form of protein shakes and/or bars, to be a snack most often used before play or practice. Although they felt that meat was a 'better' choice than 'artificial' protein powder, a meal would leave them 'stuffed' and reduce performance. A protein snack, described as 'good to keep [you] going', was quick and filling without being too much so:

'... they're good options 'cuz you're just drinking it ... you don't have to chew it or digest it 'cuz if you have like a big meal that gives you the same stuff that the shake will give you, you hafta like digest it and stuff and it like makes you feel really full and would like make you nauseous while you're playing.' (P8)

Finally, players perceived that protein powders and bars are designed for athletes and would not be used outside sports participation. They described seeing examples of protein shakes and bars and made the link to their use in hockey:

'... seeing those people [in advertisements] who are really into fitness, ... they have a lot of protein shakes and stuff in their diet, so you like transition it over to hockey.' (FG2P2)

Fast food. There was consensus among players that fast food (e.g. burgers, fries) had a negative impact on performance. Fast food was described as being 'unhealthy', 'bad' and 'junk food'. Many players were emphatic that if eaten before a game, fast food would impede performance. As one player reported: 'If you have it before a game, you're gonna feel sick'.

The players described limiting the amount of fast food they ate because they played hockey. Paradoxically, players reported that if they were not playing hockey they would eat less fast-food and restaurant meals as they would not be travelling. However, they also reported that they might eat more 'junk food', as they would no longer be concerned with the influence their diet had on their hockey performance.

\section{Theme: perceptions of foods and recovery}

Post-exercise recovery was another important influence on food and beverage choices. Beverages were considered essential to recovery. Sports drinks, protein smoothies and chocolate milk were dominant choices. Recovery was perceived to be enhanced through attention to protein intake as described previously. Protein bars were a popular choice on the way home due to their portability.

Chocolate milk. All but two of the twenty-four players reported frequently and consistently consuming chocolate milk as part of their hockey experience. Players expressed that 'most people' know chocolate milk is a good beverage choice and 'one of the best choices they could make after a game'. Players also reported that the added sugar in chocolate milk was 'ok' after a game because 'you're drained' and it would 'help with your blood sugar level' and restore energy. Some also claimed they had been 'told their entire lives' that chocolate milk was 'healthier' than other beverages with 'added sugar and stuff' and offered that as an important reason for choosing it. When asked 
where they had heard that, replies included coaches and parents.

In many instances, chocolate milk was paired with additional protein, either in the form of a protein bar or as fortified chocolate milk. Players described this combination as 'good for you' because it contained both protein and calcium.

Interestingly, many players reported that they would drink less chocolate milk if they were not playing hockey. As one player stated:

'I would drink a lot less chocolate milk, 'cuz most of the time I have a chocolate milk ... after hockey.' (P16)

Sports drinks. Sports drinks (e.g. Gatorade ${ }^{\circledR}$ ) were reported to play a significant role in recovery. Players reported frequent consumption after play and practice for thirst and to restore energy. Sports drinks were either brought in or purchased before going on the ice for use immediately after getting off the ice. Such beverages were described as always available at the arena and sometimes supplied for teams. For example, one player reported that his grandfather supplied Gatorade for the team after every game.

\section{Theme: perceptions of branding and media}

Brand associations and media influences (i.e. advertising) for Tim Horton's ${ }^{\circledR}$, Subway ${ }^{\circledR}$, McDonald' ${ }^{\circledR}$, Gatorade and chocolate milk were perceived by participants to play an important role in food choice behaviours.

Tim Horton's. Tim Horton's, Canada's largest quickservice restaurant, was described as holding an important position in the recreational hockey food experience. Players repeatedly expressed that it was healthier than McDonald's. This perception was partly based on the namesake of the franchise:

'It's just representative of like a hockey-type meal,

'cuz Tim Horton was a hockey player.' (P3)

The players also expressed allegiance to Tim Horton's due to sponsorship of Timbits ${ }^{\circledR}$ hockey (age 4-9 years) that many had experienced:

‘... played Timbits when you were like real young, so prob'ly affects your hockey career, so like oh, Tim Horton's supported me when I played hockey, so I'm gonna support them when I wanna get food.' (P4)

Tim Horton's restaurant and drive-through was reported by players to be part of the ritual of hockey participation. Players identified Tim Horton's as a food destination they requested because the food tastes good, there is a lot of variety, locations are convenient (i.e. along the highway) and food is both better and different from McDonald's. Tim Horton's was described as being a better choice than a 'fast-food place' when short of time and travelling, indicating an overlap between brand influences and convenience.

Subway. Subway sandwich shops were also considered a prominent part of the hockey experience. Subway was consistently described as a 'healthy' place to eat and players reported it being heavily advertised as the 'healthy' option:

'They advertise it like as a fitness type store ... so I think that prob'ly affects why people think it's a better option.' (FG1P6)

Interestingly, content of the photos of Subway experiences appeared to contradict the impressions of players. For example, photographs of a 'healthy' meal experience at Subway could include fountain pop, chips and/or cookies.

McDonald's. McDonald's was often referenced when comparing healthy with unhealthy choices. It was consistently offered as an example of 'unhealthy' food, described as 'empty' and as containing nothing healthy. However, there was concensus among players that it tasted good and it was frequently described as tempting.

Chocolate milk. Players also perceived chocolate milk as having a 'health halo' based on messages from advertising, coaches, experts and parents. The players reported that chocolate milk is advertised as something you have with exercise. Moreover they noted the absence of similar advertisements for the benefits of white milk, so did not think to buy white milk:

'And it's like, you don't really see like advertisements for like plain milk, how it's like good for you. It's all chocolate milk, how it's better for you, so you don't really think to have white milk, 'cuz it's not really said to you.' (FG1P7)

Gatorade. Gatorade was reported to be advertised as a beverage specifically intended for hockey players and as a product for athletes that was not appropriately used outside sports participation:

'It's advertised as like a hockey drink.' (P20)

The players described that commercials frequently employ well-known professional players and reported that advertisements suggest Gatorade would improve performance.

Knowledge and advertising. Some players suggested knowledge of nutrition protected them from being susceptible to advertising. The players suggested that professional hockey players got sponsorship offers because they were good players. Interestingly, players expressed scepticism that professional sports figures would eat the unhealthy foods they endorse through media:

'Like there's some players that will do like a commercial for like McDonald's or like a fast-food restaurant sometimes and you know that they don't eat there.' (P14) 
Theme: morality and values

Players frequently described foods used morally weighted language. Fast food, in particular, was described as 'tempting', being something 'you want that is not good for you' and causing feelings of 'guilt'. Foods being described as 'treats' and 'rewards' were perceived as 'unhealthy' and 'bad' choices. McDonald's food was consistently labelled as 'bad', 'empty' and 'unhealthy'. However, it was also consistently described as 'tasting good' while being 'bad for you' and 'tempting'. For example, when discussing a photograph of a McDonald's meal, focus group participants said:

'It's like the meal of shame.' (FG1P1)

'Double Big Mac's.' (FG1P2)

'Yeah!' (FG1P7)

\section{Theme: tournament influences}

Players reported that attending tournaments influenced their eating behaviours in several ways, including time constraints, convenience and frequent restaurant meals.

Time constraints and convenience. Participants described fast food as a quick, easy and convenient part of the hockey tournament experience. Time constraints between games allowed little more than drive-through purchase of fast food to eat, as it is convenient and accessible. There was mixed response from the players around how often they ate fast food, but there was a general consensus that it was not healthy for you and that you should not eat too much of it.

Tournament team meals. Restaurant team meals were a common experience when attending tournaments. Team meals after a game were described as typical and often occurred as a 'chain reaction' as no one wanted to be the player who did not go with the team. As one player described:

'... if one person says it and another person says "yeah we'll go" and your friends kind of ... then like the whole team ends up going and you don't really want to be like that one guy who doesn't go.' (FG2P4)

Players also reported eating similar types of food to teammates, not, they claimed, because they were being influenced but because they like the same types of food.

\section{Parents' perceptions of hockey players' experiences}

Sample

Five parents, all female, participated in one-on-one interviews to discuss photographs exhibited: three participants' parents and two non-participants' parents.

\section{Findings}

There was a mixed response to the content of players' photographs. Two expressed surprise at the amount of fast food and three indicated it was 'about what they expected':

'The pizza didn't surprise me.' (PT2)

'They're fairly accurate from what I've seen.' (PT1)

'The amount of fried food surprised me. 'Cuz I know that's what you get at an arena, it still surprised me that there was so much.' (PT3)

Dominant themes that emerged around parents' perceptions of influences on the players included recreational facility food offerings and time constraints.

Theme: recreational facility food offerings

Parents agreed with the hockey players that recreation facility food offerings were generally unhealthy:

' $\ldots$ just trying to think of all the different arenas we go to ... there are not a lot of healthy options.' (PT3)

'... if your only choice is chicken fingers and fries or a burger, you're going to choose chicken fingers or a burger, right?' (PT2)

Like players, parents expressed an expectation to be offered 'traditional arena-type foods', such as French fries, poutine and slushies. As one parent described:

'People go "oh yeah, when you go to this arena they got really good poutine". If that's what you remember an arena for, right, that's not good.' (PT2)

Parents also perceived that availability of such foods was part of the overall hockey experience and those attending a game would be resistant to any changes to this experience. Similarly, siblings and other children attending as spectators expected to be 'allowed' a food or beverage choice from either the recreation facility or a drivethrough. This aligns with the players' perception of recreation food offerings as mainly relevant for spectators than themselves. Although, seeing traditional arena foods as a 'treat' or 'reward' for the players themselves was common to player and parent perspectives.

\section{Theme: time constraints}

Parents described time constraints as a constant challenge affecting the hockey player's eating behaviour. Practice, play and travel schedules that limited time for meal preparation and family dinners resulted in regular food purchases outside the home.

\section{Discussion}

The current research set out to explore perceived influences on adolescent food behaviours associated with participating in recreational ice hockey at levels above house league. This included exposure to the recreational 
facility food environment as well as the broader physical and social environments.

A priori, the recreational facility food environment was expected to have a powerful influence on food behaviours of adolescent hockey players due to high levels of exposure. However, findings indicated that performance, recovery, branding/media, morality and travel were considered stronger influences on food choices of participants.

In most cases, food perceptions were described as being informed by knowledge. The hockey players in the current study regularly acted on information relevant to their performance and recovery when making food choices. The difference in the perception of protein between those who had nutritional guidance and those who did not indicates how such information can influence behaviour. Nevertheless, as the literature supports, knowledge alone is not sufficient to drive behaviours ${ }^{(33,50,51)}$. As has been seen elsewhere, participants demonstrated that nutrition information must be associated with activities or consequences that are relevant and meaningful to the adolescents $^{(34,52)}$. The source providing the information to players was perceived as expert and was offered in a context that was relevant for the players. Interestingly, those players who described planning a future hockey career also described themselves as very strictly adhering to the guidelines provided, suggesting that perceived importance can also influence the level of adoption. These findings support prior research on benefits of and barriers to healthy eating for adolescents, suggesting that to motivate healthful eating in adolescents their perceived benefits must be understood ${ }^{(53)}$.

The nutritionist that spoke to the subset of six players also offered input around chocolate milk. Yet, there was no described difference in chocolate milk consumption between the two groups of players. As this was not new information, the players had already internalized the perceived benefits of chocolate milk consumption from other sources. It demonstrates that while perception of a distinct benefit is needed to influence behaviour change, a range of information sources can influence perceptions. This underlines the importance of evidence-based sources and supports the use of a multipronged approach to encourage adoption of healthy eating behaviours in adolescents $^{(54)}$

The players' perceptions around healthy and unhealthy choices did not consistently translate into behaviour. Perceived healthy foods were chosen when they would directly influence performance; however, that knowledge did not prevent the players from eating perceived unhealthy choices at other times. For example, the photographs of Subway experiences indicate that while the players perceive this restaurant as being healthy, the choices did not reflect described perceptions.

Language used by the players around certain foods and food behaviours indicate moral values are an important influence. Previous research with Canadian teens found that fast-food consumption was considered unhealthy, eating fast food was judged negatively and moral boundaries were applied to consumption decisions, hence accessibility and availability were not the sole drivers of food choice ${ }^{(55)}$. For the adolescent hockey players in the current study, their ranking of fast-food outlets at travel stops reflects the moral dictates that are part of their decision-making process. The participants also made moralistic judgements of their own behaviour; unhealthy choices were considered 'bad' behaviour and associated with feelings of guilt. These negative judgements and the associated feelings of guilt are consistent with other research $^{(53,55)}$.

The social environment was also an important influence on food behaviours. Being part of the hockey team group appeared to be more dominant than individual preferences as demonstrated by the social desirability of being perceived as part of the group. The similarity of food choices at tournaments can be interpreted as adopting a consensus, or as an indication that peers have similar values around food choices ${ }^{(56)}$. Attending a hockey game was also perceived by players and parents as a social experience. Associated situational norms ('arena foods') and social norms ('part of the experience of watching a game') directly influenced food choices ${ }^{(6,57,58)}$. Results from the present study indicate that modification of social norms is required. The importance of performance to adolescent athletes presents an opportunity to shift food norms associated with social and environmental aspects of recreation.

Another finding that appears consistent with earlier research is that adolescents involved in sports have high intakes of fast foods and sugar-sweetened beverages ${ }^{(12,13)}$. Meals consumed away from home as part of team travel and due to time constraints were described by players and parents as contributing to this high intake. However, intake of sugar-sweetened beverages may also result from purposeful intake of chocolate milk and sports drinks. Intake of these sugar-sweetened beverages is normative for this population and has even been described as 'institutionalized' ${ }^{,(12)}$. Given the high level of play, there is little doubt that energy demands of the study population compensate for the energy intake associated with sweetened beverages. However, the long-term implications of these behaviours are unknown and warrant further investigation.

Adolescent susceptibility to advertising has been observed by others ${ }^{(59)}$. Marketing influences described by the players clearly support the call for policy restricting food and beverage marketing to children and adolescents across diverse settings ${ }^{(60,61)}$. The current research also demonstrates the potential influence on adolescents' eating behaviour of targeted sport-specific marketing, whether child/adolescent directed or not, and sponsorship for highly popular sports, like hockey in Canada ${ }^{(62-65)}$. Player 
response to sport-specific marketing also supports policy restricting any food marketing exposure in settings where children and adolescents spend time, like recreation facilities.

It was apparent from all participants that some foods were 'halo' foods. These included chocolate milk and specific restaurant options. Central to this perception was the strong influence of advertising. The influence of media advertising on children's eating behaviour has been observed elsewhere ${ }^{(66,67)}$. Importantly, the finding that conferring 'halo' status impacted intake choices in the current research suggests that advertising can influence the perception of healthful eating behaviours and is consistent with other research ${ }^{(68,69)}$. Implications are twofold. First, halo status can be leveraged for increased consumption of healthy choices. However, if halo status can be conferred when a product is linked to other activities that can be perceived as healthy such as playing sports, this suggests the need for marketing restrictions around what is labelled a healthy choice and the context in which foods are marketed ${ }^{(70)}$.

Both players and parents indicated recreation facilities in Ontario 'should' offer healthy options. Policies limiting the marketing and sale of unhealthy foods and beverages may be an effective approach to influence eating behaviours within recreation facilities and some Canadian provinces have instituted voluntary guidelines ${ }^{(25-27,71,72)}$. Limiting sponsorship promotions of unhealthy food and beverage options has also been identified as a viable option $^{(73)}$. However, change in one environment may not be sufficient to achieve desired behaviour changes. Moreover, the hockey participants described high exposure to unhealthy foods, yet limited consumption of recreation facility offerings. The perceptions these players place around the value of healthy food choices for performance could be leveraged to influence change. This has implications for policies and processes relating to player training and food retail and media environments.

These results reinforce the value and necessity of including an adolescent voice when researching environments that influence their eating behaviours in order to inform appropriate and effective policy measures.

\section{Strengths/limitations}

Timeliness is a key strength of the present study. Many jurisdictions across Canada are considering policy/guidelines to increase healthy food offerings in recreation facilities. The present study can inform those guidelines as well as broader intervention approaches to support such guidelines. Another study strength is its unique approach: using key informants who typically have little influence on policy or regulations directly affecting them, and photovoice methodology to depict their food environment. This informed, experiential viewpoint provides insights that could not be obtained using other methodological approaches. The addition of a stakeholder (parent) perspective also provides opportunity to contextualize the experiences and perspectives of the adolescents to a greater degree than data from the adolescents alone.

There are potential study limitations that must be considered. Although study participants represented five hockey leagues and twelve teams, qualitative approaches are meant to describe a range of perceptions and may not be generalizable to the adolescent hockey population outside the region of study or level of play. Only two participants were female, reducing the possibility of distinguishing any distinctly gender-oriented experiences. No male parents were recruited to participate, limiting parent perceptions to female parents.

Due to the open and interactive atmosphere of the recreation environment, and some participation of teammates, there could have been inter-participant influence on the data collected. While teams may cross paths at tournaments or recreation facilties when travelling, this is highly unlikely to result in confounding or collusion. A key aim of the individual interviews prior to group discussion was to reduce the opportunity for inter-participant influence when contextualizing the photographs around participants' lived experience ${ }^{(73)}$

One of the challenges recruiting participants was the potential for bias caused when parents refused to allow interested children to participate. In some cases, this centred on not wanting their child's food behaviour documented. One mother responded, 'Oh no, I wouldn't want you to know what I allowed [child's name] to eat last night after the game!' As the gatekeepers, these parents were concerned that they would be judged for the eating behaviours associated with their child participating in recreational hockey.

\section{Conclusions}

Recreation facilities are only one of a range of environments that influence the eating behaviours of adolescent hockey players. Yet, this does not exempt the recreation facility environment from supporting healthy eating behaviours. Both the hockey players and their parents perceive Ontario recreation facilities to be unhealthy food environments, supporting the need for policy to ensure that environments where children and adolescents play provide a healthful food environment.

Young hockey players, particularly those who had received nutrition education, were highly motivated by perceived benefits of healthy eating on performance and reported that they did not generally make food purchases at recreation facilities. Parents, coaches, educators and food retail can leverage the values and perceptions of adolescent athletes to support healthy food choices. Indeed, recreation food facility management and vendors may be missing a significant opportunity through not providing the healthy food options that players value. 
Player perceptions and behaviours around brand and product messaging support the literature on adolescent vulnerability to advertising and promotion, advancing the call for policy restricting food marketing to children and adolescents, both as directed marketing and through general exposure. The successful marketing of chocolate milk and specific fast-food franchises as 'healthy' choices suggests the potential for using messaging, if evidencebased, to support healthy eating. However, it also indicates the need for policy around 'heathful' marketing to ensure 'health halos' are bestowed only on products that are legitimately healthy.

The present study supports the need for both policy within recreation environments as a step towards healthier environments and ongoing efforts to restrict marketing to children and adolescents. It also underscores the merit of including adolescents' perception in public health discussions that affect them.

\section{Acknowledgements}

Acknowledgements: The authors would like to thank all study participants for their valuable contributions, and the coaches and league representatives who supported participant recruitment. They are grateful to Jessica Lieffers $\mathrm{PhD}$, RD (School of Pharmacy and Nutrition, University of Saskatchewan, SK, Canada) for her analytic support as a second reader. Financial support: This research received no specific grant from any funding agency in the public, commercial or not-for-profit sectors. Conflict of interest: None. Authorship: M.S.C. formulated the research, designed the study, collected the data, conducted the qualitative analyses, interpreted the results and prepared the manuscript. R.M.H. participated in the study design and data interpretation and critically reviewed the manuscript. Ethics of buman subject participation: This study was conducted according to the guidelines laid down in the Declaration of Helsinki and all procedures involving human subjects were approved by the University of Waterloo Office of Research Ethics. Written informed consent was obtained from all subjects.

\section{References}

1. Lobstein T, Baur L \& Uauy R (2004) Obesity in children and young people: a crisis in public health. Obes Rev 5, Suppl. 1, 4-85.

2. Sheperd J, Harden A, Rees R et al. (2006) Young people and healthy eating: a systematic review of research on barriers and facilitators. Health Educ Res 21, 239-257.

3. Storey KE, Forbes LE, Fraser SN et al. (2009) Diet quality, nutrition and physical activity among adolescents: the Web-SPAN (Web-Survey of Physical Activity and Nutrition) project. Public Health Nutr 12, 2009-2017.

4. Bauer KW, Larson NI, Nelson MC et al. (2009) Socio-environmental, personal and behavioural predictors of fast-food intake among adolescents. Public Health Nutr 12, $1767-1774$.
5. World Health Organization (2016) Report of the Commission on Ending Childhood Obesity. Geneva: WHO.

6. Salvy SJ, de la Haye K, Bowker JC et al. (2012) Influence of peers and friends on children's and adolescents' eating and activity behaviors. Physiol Behav 106, 369-378.

7. van der Horst K, Oenema A, Ferreira I et al. (2006) A systematic review of environmental correlates of obesityrelated behaviours in youth. Health Educ Res 22, 203-226.

8. Taveras EM, Berkey CS, Rifas-Shiman SL et al. (2005) Association of consumption of fried food away from home with body mass index and diet quality in older children and adolescents. Pediatrics 116, e518-e524.

9. Bowman SA, Gortmaker L, Ebbeling CB et al. (2004) Effects of fast-food consumption on energy intake and diet quality among children in a national household survey. Pediatrics 113, 112-118.

10. French SA, Story M, Nneumark-Sztainer D et al. (2001) Fast food restaurant use among adolescents: associations with nutrient intake, food choices and behavioral and psychosocial variables. Int $J$ Obes Relat Metab Disord 15 , 1823-1833.

11. Woodruff SJ \& Hanning RM (2009) Effect of meal environment on diet quality rating. Can J Diet Pract Res 270, 118-124.

12. Nelson TF, Stovitz SD, Thomas M et al. (2011) Do youth sports prevent pediatric obesity? A systematic review and commentary. Curr Sports Med Rep 10, 360-370.

13. Cavadini C, Decarli B, Grin J et al. (2000) Food habits and sport activity during adolescence: differences between athletic and non-athletic teenagers in Switzerland. Eur J Clin Nutr 54, Suppl. 1, S16-S20.

14. Naylor PJ, Bridgewater L, Purcell M et al. (2010) Publicly funded recreation facilities: obesogenic environments for children and families? Int J Environ Res Public Health 7, 2208-2221.

15. Chaumette P, Morency S, Royer A et al. (2009) Food environment in sport, recreational and cultural facilities in Quebec City: a look at the situation. Can J Public Health 100, 310-314.

16. Fung C, McIsaac J-L, Kuhle S et al. (2013) The impact of a population-level school food and nutrition policy on dietary intake and body weights of Canadian children. Prev Med 57, 934-994.

17. Nanney MS, MacLehose RF, Kubik MY et al. (2016) School obesity prevention policies and practices in Minnesota and student outcomes: a longitudinal cohort study. Am J Prev Med 51, 656-663.

18. Jaime PC \& Lock K (2009) Do school based food and nutrition polcies improve diet and reduce obesity? Prev Med 48, 45-53.

19. Masse LC, Niet-Fitzgerald JE, Watts AW et al. (2014) Associations between the school food environment, student consumption and body mass index of Canadian adolescents. Int J Behav Nutr Phys Act 11, 29.

20. Hawkes C, Smith TG, Jewell J et al. (2015) Smart food policies for obesity prevention. Lancet 385, 2410-2421.

21. Story M, Nanney MS \& Schwartz MB (2009) Schools and obesity prevention: creating school environments and policies to promote healthy eating and physical activity. Millbank $Q$ 87, 71-100.

22. Vander Wekken S, Sorensen S, Meldrum J et al. (2012) Exploring industry perspectives on the implementation of a provincial policy for food and beverage sales in publicly funded recreation facilities. Health Policy 104, 279-287.

23. Olstad DL, Raine KD \& McCarger LJ (2012) Adopting and implementing nutrition guidelines in recreation facilities: public and private sector roles. A multiple case study. BMC Public Health 12, 376.

24. Institute of Medicine, Committee on Prevention of Obesity in Children and Youth, Food and Nutrition Board \& Board 
on Health Promotion and Disease Prevention (2005) Preventing Childhood Obesity: Health in the Balance, [JP Koplan, CT Liverman and VI Craak, editors]. Washington, DC: The National Academies Press.

25. HealthyFamiliesBC (2014) Healthier Choices in Vending Machines in BC Public Buildings Policy. http://www. healthlinkbc.ca/foodguidelines (accessed May 2016).

26. Alberta Health (2012) Nutrition Guidelines for Children and Youth 2012. http://www.health.alberta.ca/documents/ Nutrition-Guidelines-AB-Children-Youth.pdf (accessed May 2016).

27. Government of Nova Scotia (2015) Healthy eating in recreation and sport settings guidelines. http://www. recreationns.ns.ca/guidelines-for-healthy-eating-in-recreationand-sport-settings/ (accessed May 2016).

28. Butland B, Jebb S, Kopelman P et al. (2007) Foresight Tackling Obesities: Future Choices - Project Report, 2nd ed. London: Government Office for Science.

29. Naylor P-J, Vander Wekken S, Trill D et al. (2010) Facilitating healthier food environments in public recreation facilities: results of a pilot project in British Columbia, Canada. J Park Recreat Adm 28, 37-58.

30. Olstad DL, Downs SM, Raine KD et al. (2011) Improving children's environments: a survey of adoption and implementation of nutrition guidelines in recreation facilities. BMC Public Health 11, 423.

31. Olstad DL, Raine KD \& McCarger LJ (2013) Adopting and implementing nutrition guidelines in recreation facilities: tensions between public health and corporate profitability. Public Health Nutr 16, 815-823.

32. Neumark-Sztainer D, Story M, Perry C et al. (1999) Factors influencing food choices of adolescents: findings from focus-group discussions with adolescents. J Am Diet Assoc 99, 929-934.

33. Thakur N \& D'Amico F (1999) Relationship of nutritional knowledge and obesity in adolescence. Fam Med 31, 122-127.

34. Turconi G, Guarcell M, Maccarini L et al. (2008) Eating habits and behaviors, physical activity, nutritional and food safety knowldege and beliefs in an adolescent Italian population. J Am Coll Nutr 27, 31-43.

35. Rasmussen M, Krolner R, Klepp K-I et al. (2006) Determinants of fruit and vegetable consumption among children and adolescents: a review of the literature. Part I: Quantitative studies. Int J Behav Nutr Phys Act 3, 22.

36. Krolner R, Rasmussen M, Brug J et al. (2011) Determinants of fruit and vegetable intake consumption among children and adolescents: a review of the literature. Part II: Qualitative studies. Int J Behav Nutr Phys Act 8, 1162.

37. Harris JE, Gleason PM, Sheean PM et al. (2009) An introduction to qualitative research for food and nutrition professionals. J Am Diet Assoc 109, 80-90.

38. Martin N, Garcia AC \& Leipert B (2010) Photovoice and its potential use in nutrition and dietetic research. Can J Diet Pract Res 71, 95-97.

39. Lal S, Jarus T \& Suto MJ (2012) A scoping review of the photovoice method: implications for occupational therapy research. Can J Occup Ther 79, 181-190.

40. Catalani C \& Minkler M (2010) Photovoice: a review of the literature in health and public health. Health Educ Behav 37, 424-451.

41. Linton LS, Edwards CC, Woodruff SI et al. (2014) Youth advocacy as a tool for environmental and policy changes that support physical activity and nutrition: an evaluation study in San Diego County. Prev Chronic Dis 11, 130321.

42. Wang CC (1999) Photovoice: a participatory action research strategy applied to women's health. $J$ Womens Health $\mathbf{8}$, 185-192.
43. Wang CC (2006) Youth participation in photovoice as a strategy for community change. J Community Pract 14, 147-161.

44. Plunkett R, Leipert BC \& Ray SL (2013) Unspoken phenomena: using the photovoice method to enrich phenominological inquiry. Nurs Inq 20, 156-164.

45. Cresswell JW (2013) Qualitative Inquiry and Research Design: Choosing Among Five Approaches, 3rd ed. Thousand Oaks, CA: SAGE Publications, Inc.

46. Kvale S \& Brinkmann S (2009) Interviews Learning the Craft of Qualitative Research Interviewing, 2nd ed. Thousand Oaks, CA: SAGE Publications, Inc.

47. Edward K-L \& Welch T (2011) The extension of Colaizzi's method of phenomenological enquiry. Comtemp Nurse 39, $163-171$.

48. Miles MB, Huberman AM \& Saldana J (2014) Qualitative Data Analysis: A Methods Sourcebook. Thousand Oaks, CA: SAGE Publications, Inc.

49. Creswell JW \& Miller DL (2000) Determining validity in qualitative inquiry. Theory Pract 39, 124-130.

50. Reading KJ, McCargar LJ \& Marriage BJ (1999) Adolescent and young adult male hockey players: nutrition knowledge and education. Can J Diet Pract Res 60, 166-169.

51. Walsh M, Cartwright L, Corish C et al. (2011) The body composition, nutritional knowledge, attitudes, behaviors, and future education needs of senior schoolboy rugby players in Ireland. Int J Sport Nutr Exerc Metab 21, 365-376.

52. Doyle-Lucas AF \& Davy BM (2011) Development and evaluation of an educational intervention program for preprofessional adolescent ballet dancers: nutrition for optimal performance. J Dance Med Sci 15, 65-75.

53. O'Dea JA (2003) Why do kids eat healthful food? Perceived benefits of and barriers to healthful eating and physical activity among children and adolescents. J Am Diet Assoc 103, 497-501.

54. Philippou E, Middleton N, Pistos C et al. (2017) The impact of nutrition education on nutrition knowledge and adherence to the Mediterranean diet in adolescent competitive swimmers. J Sci Med Sport 20, 328-332.

55. McPhail D, Chapman GE \& Beagan BI (2011) Too much of that stuff can't be good': Canadian teens, morality, and fast food consumption. Soc Sci Med 73, 301-307.

56. Contento IR, Williams SS, Michela JL et al. (2006) Understading the food choice process of adolescents in the context of family and friends. $J$ Adolesc Health 38, 575-582.

57. Robinson E, Harris E, Thomas J et al. (2013) Reducing high calorie snack food in young adults: a role for social norms and health based messages. Int J Behav Nutr Phys Act 10, 73 .

58. Robinson E, Fleming A \& Higgs S (2014) Prompting healthier eating: testing the use of health and social norm based messages. Health Psychol 33, 1057-1064.

59. Cairns G, Angus K, Hasting G et al. (2013) Systematic reviews of the evidence on the nature, extent and effects of food marketing to children. A retrospective summary. Appetite 62, 209-215.

60. World Health Organization (2010) Set of Recommendation on the Marketing of Foods and Non-Alcoholic Beverages to Children. Geneva: WHO.

61. Rain KD, Lobstein T, Landon J et al. (2013) Restricting marketing to children: concensus on policy interventions to address obesity. J Public Health Policy 34, 239-253.

62. Jane B \& Gibson K (2017) Corporate sponsorship of physical activity programmes: part of the solution or part of the problem? J Public Health (Oxf). Published online: 7 June 2017. doi: 10.1093/pubmed/fdx065.

63. Pettigrew S, Rosenberg M, Ferguson R et al. (2013) Game on: do children absorb sports sponshorship messages? Public Health Nutr 16, 2197-2204. 
64. Kelly B, Bauman AE \& Baur LA (2014) Population estimates of Australian children's exposure to food and beverage sponsorship of sports clubs. J Sci Med Sport 17, 394-398.

65. Smith M, Jenkin G, Signal L et al. (2014) Consuming calories and creating cavities: beverages NZ children associate with sport. Appetite 81, 209-217.

66. Boyland EJ \& Halford JC (2013) Televison advertising and branding: effects on eating behaviour and food preferences in children. Appetite 62, 236-241.

67. Chernin A (2008) The effects of food marketing on children's preferences: testing the moderating roles of age and gender. Ann Am Acad Polit Soc Sci 615, 102-118.

68. Harris JL, Haraghey KS, Lodoice M et al. (2017) Teaching chldren about good health? Halo effects in child directed advertisements for unhealthy food. Pediatr Obes. Published online: 27 October 2017. doi: 10.1111/ijpo.12257.
69. Dixon M, Scully Niven P et al. (2014) Effects of nutrient content claims, sports celebrity endorsements and premium offers on pre-adolescent children's food preferences: experimental research. Pediatr Obes 9, e47-e 57.

70. Kelly B, Baur LA, Bauman AE et al. (2011) Food company sponsors are kind, generous and cool': (mis)conceptions of junior sports players. Int J Behav Nutr Phys Act 8, 95.

71. Capacci S, Mazzocchi M, Shankar B et al. (2012) Policies to promote healthy eating in Europe: a structured review of policies and their effectiveness. Nutr Rev 70, 188-200.

72. Kelly B, King L, Bauman AE et al. (2014) Identifying important and feasible policies and actions for health at community sports clubs: a consensus-generating approach. J Sci Med Sport 17, 61-66.

73. Gibson F (2007) Conducting focus groups with children and young people: strategies for success. J Res Nurs 12, 473-483. 